\title{
Erratum to: Accounting Standards for Business Enterprises \\ No. 20-Business Combinations
}

\section{Erratum to:}

Chapter 24 in: L. Riccardi, China Accounting Standards, DOI 10.1007/978-981-10-0006-5_24

The book was inadvertently published with identical contents in Chapters-24 and 25 . The erratum chapter and the book has been updated with the revised content for Chapter-24.

\footnotetext{
The updated original version of the book was revised: Content of Chapter-24 was updated: The original PDF is available at: 10.1007/978-981-10-0006-5_24 